\title{
CAPítTULO 2
}

\section{POR QUE EXISTE PRECONCEITO?}

As análises da psicologia social sobre as causas do preconceito consideram desde seus aspectos individuais, afetivos e cognitivos, até os aspectos coletivos das relações entre grupos. Essas análises são históricas, variam em função dos contextos de relações sociais nas quais surgiram. As primeiras explicações surgem na década de 1920, quando o tema passa a ser objeto de estudo científico. Naquele momento, o preconceito era entendido como "problema histórico", vinculado à explicação da dominação colonial branca; ele gerava estudos para a identificação de características dos "grupos atrasados", e era concebido como uma resposta natural a "pessoas inferiores". Entre 1920 e 1930, a ideia de dominação branca é posta em xeque e o preconceito passa a ser um problema social, explicado como algo irracional e injustificável. Nas duas décadas seguintes, sob a influência da psicanálise, as explicações procuram encontrar elementos psicológicos inconscientes e universais no preconceito. Na década de 1950, após o nazifascismo, o interesse recai sobre as personalidades suscetíveis ao preconceito, sendo ele entendido como uma necessidade patológica do ser humano. Na década seguinte, ele passa a ser entendido como uma norma social, as explicações para sua existência focam a socialização ou aprendizado. Na década de 1970, ganham destaque as abordagens em termos de relações entre grupos, 
sendo o preconceito entendido como expressão de interesses grupais. Na década 1980, a questão histórica passa a ser novamente a da inevitabilidade e universalidade do preconceito, mas os estudos focam os processos de categorização social (DUCKITT, 1992). Mais recentemente, nas décadas de 1990 e 2000, ganham destaque as explicações do preconceito como algo automático, com ênfase na perspectiva teórico-metodológica das neurociências. Finalmnete, a partir de 2000, o preconceito é explicado como uma intensa e muitas vezes irracional hostilidade intergrupal, com destaque teórico simultâneo para os processos cognitivo-afetivos e os sociais de competição e desigualdades, presentes em teorias como a da Dominância Social e a da Justificação do Sistema (DUCKITT, 2010).

Infelizmente, ainda não é possível fazer um levantamento histórico desse tipo sobre as perspectivas de análise do preconceito na psicologia do Brasil, pois temos uma produção ainda pequena (SACCO, DE PAULA COUTO, \& KOLLER, 2016). No entanto, fizemos uma busca de publicações cujo título contivesse o descritor "preconceito" nas bases de dados SciELO, Periódicos CAPES, LILACS e PsycInfo no período de 05 a 12 de abril de 2020, adotando o corte temporal de publicações registradas entre 1950 e 2019. Foram encontradas um total de 701 publicações disponíveis nas bases de dados. Destas, foram eliminadas as repetições e artigos registrados duas vezes ou mais em outro idioma, bem como uma publicação sem registro. Resultaram 360 publicações válidas. Dentre elas encontram-se artigos publicados em periódicos, teses, dissertações, resenhas, livros, capítulos de livros e dossiês históricos. A única base na qual não foram encontradas publicações para o descritor escolhido foi a PsycInfo.

Os resultados obtidos estão sistematizados por décadas (ver Figura 2). A produção nacional se inicia nos anos 50 do século passado. Nessa década, apenas cinco textos foram encontrados na nossa busca, todos escritos por Lewis Hanke, um norte americano dedicado à historiografia da América Latina colonial. Nestes textos, ele analisa o preconceito de raça, sobretudo contra os índios na América Latina. Na década de 1960, apenas um texto emergiu da busca, trata-se de um artigo de Marie Anne W. Taddei sobre a interação dos judeus e o preconceito antissemita, publicado na Revista de Psicologia Normal e Patológica em 1969. Esse texto é provavelmente o primeiro artigo sobre preconceito publicado num periódico de psicologia no Brasil. Na década de 1970, temos também só uma publicação sobre preconceito contra mulheres operárias em Joinville, escrito por Afonso Imhof, historiador catarinense. Na década de 1980, foram encontrados sete artigos, quatro publicados em periódicos de psicologia, sendo um deles uma proposta de abordagem "psicobiosocial" da experiência de preconceito, escrito 
por Marcio Fernando Strada Sant'Anna, talvez o primeiro com uma abordagem que integra o "psico" ao "social" sobre o tema ${ }^{\mathrm{VIII}}$. Há também textos de destaque como "Raça: conceito e preconceito" de Eliane Azevêdo e "Escravidão, racismo e preconceito" de Petrônio José de Aguiar.

Na década de 1990, finalmente o tema passa a se tornar objeto de um maior número de publicações em periódicos nacionais, ao todo, foram localizadas 30 publicações. Cabe referir que foi também nessa década que o Brasil se reconheceu oficialmente como país racista (TELLES, 2004). Dentre os trabalhos, há sete artigos que foram publicados em periódicos de psicologia e duas teses ou dissertações (não especificamos essa distinção na busca) defendidas na psicologia. Nos títulos encontrados, há uma maior concentração de publicações sobre preconceito de marca, seguindo a linha teórica de Oracy Nogueira, e de trabalhos relacionando AIDS e preconceito. Mas aparecem também, de forma inaugural, trabalhos sobre preconceito contra outras minorias, a exemplo de pessoas com deficiência, idosos, pessoas com transtornos psiquiátricos e homossexuais. Destaque aqui para o artigo "Preconceito, indivíduo e sociedade" de José Leon Crochik, que integra elementos da teoria cognitiva de Gordon Allport com outros das Teoria da Personalidade Autoritária da Escola de Frankfurt.

Entre 2000 e 2009, foram encontrados 92 registros. Nos seus títulos apenas as palavras "preconceito", "histórias", "racial", "estudo", “educação", "Brasill", "valores", "discriminação" e "análise" aparecem pelo menos cinco vezes (não consideramos pronomes e preposições nessa análise). Esse dado indica a ausência de uma linha de pesquisa com análises sistemáticas sobre um dentre os vários aspectos do preconceito, trata-se de uma proliferação de focos de análise ou de grupos-alvo, a exemplo de "preconceito linguístico", "racial" (sendo este o mais pesquisado, pois aparece em sete títulos), "deficiência", "homossexualidade", "identidades", entre outros. Dentre os 92 trabalhos, 44 foram publicados na área de psicologia, sendo 38 artigos e seis dissertações/teses.

Entre 2010 e 2019 foram encontrados 224 trabalhos publicados tendo "preconceito" no título. Considerando as palavras que se repetem pelo menos 10 vezes nesses 224 títulos temos: "preconceito", "racial", "contra", "sociais", "discriminação", "educação", "homossexuais", "sexual”, "Brasil", "diversidade” e "pessoas". Ou seja, os temas do preconceito contra homossexuais e da diversidade sexual ganham destaque equivalente ao do preconceito racial, começando a se constituir uma linha sistemática de investigação e publicação. Desses trabalhos, 83 foram publicados/realizados no âmbito da psicologia, sendo 73 artigos e 10 dissertações/teses. 
Na Figura 2, podemos ver que a produção nacional até 2019 foi de 360 artigos científicos. A título de comparação, num levantamento feito por Dovidio, Hewstone, Glick e Esses (2010) somente na base de dados PsychInfo em língua inglesa, usando os termos "estereótipos" e preconceito", apenas na década de 1930, foram encontrados 29 trabalhos, valor que subiu para 1829 entre os anos 2000 e 2008. Nossos dados, ainda que de forma mais modesta, também mostram um crescimento exponencial. Da década de 1980 para a de 1990 , tivemos $428 \%$ de aumento na produção científica sobre preconceito. Entre 1990 e 2009, a produção cresceu $303 \%$ e, de 2010 a 2019, o crescimento foi de 242\%. Importante referir que 141 desses 360 trabalhos, ou seja, 39\% da produção científica nacional sobre preconceito desde a década de 1950 nas bases de dados consultadas, foi da psicologia.

Figura 2: Número de trabalhos científicos publicados no Brasil em cujo título aparece a palavra "preconceito", organizados por década

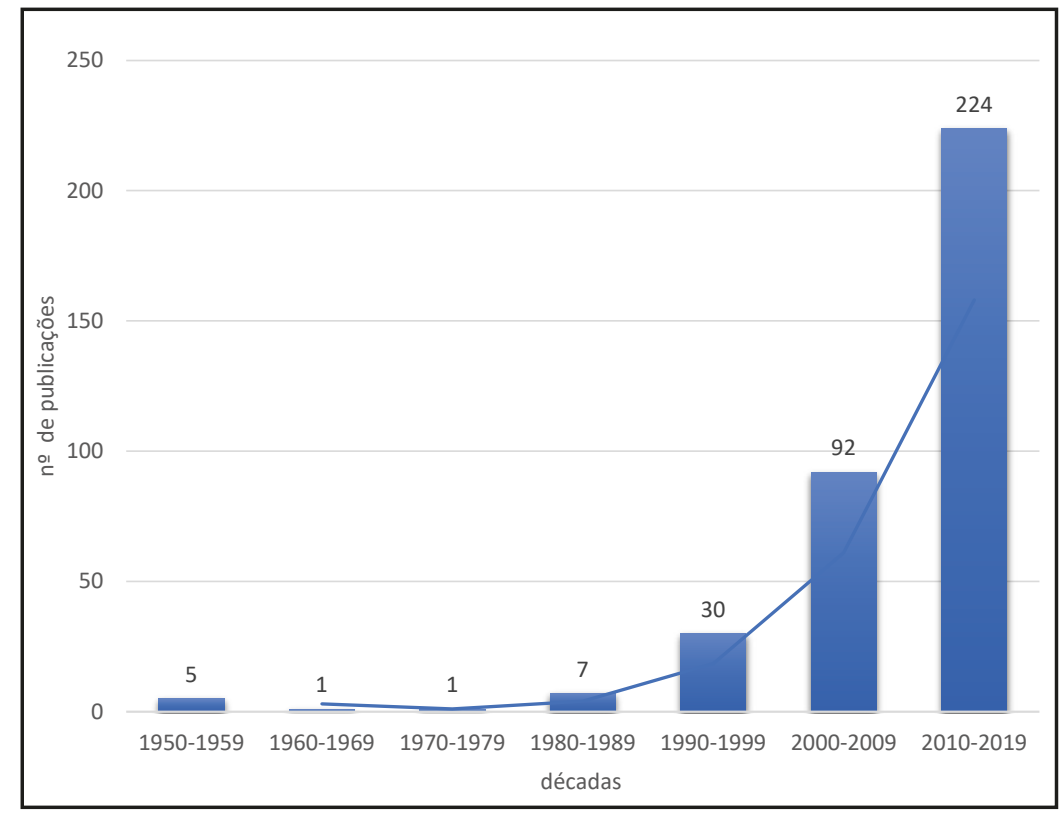

Em seguida, aprofundaremos as análises das causas do preconceito considerando as explicações a partir da década de 1950, quando o tema começa a ser analisado de forma mais sistemática na psicologia social. Nessa época, o problema central a ser entendido eram os processos cognitivos subjacentes aos estereótipos e preconceitos nas percepções julgamentos sociais. Vimos que o 
preconceito era entendido como um tipo de patologia, de modo que se indagava se era possível não ser preconceituoso.

\section{1. É NORMAL PRÉ-JULGAR?}

Quando se estuda o preconceito numa perspectiva psicossocial, considera-se igualmente relevantes as contribuições da psicologia e as das ciências sociais. Nessa seara, é incontornável a leitura do livro clássico "A Natureza do Preconceito", escrito por Gordon Allport em 1954. O segundo capítulo desse livro trata da normalidade do prejulgamento ou da preconcepção, que são as bases semânticas do nosso objeto - o preconceito. O texto se inicia com uma pergunta: "Por que os seres humanos escorregam tão facilmente no preconceito"? A resposta de Allport é a de que isso acontece em função de dois dos componentes essenciais do preconceito: a hostilidade e a generalização falha ou errônea, mecanismos naturais e inevitáveis do pensamento ou cognição humana, que estariam na base do preconceito.

A abordagem de Allport é focada em aspectos estritamente cognitivos. Nesse sentido, ele desenvolve seu argumento afirmando que a origem do preconceito é a necessidade humana de pertencer e se relacionar com grupos, separando o seu grupo do grupo dos outros. Esta separação faz com que o grau de diferença entre os grupos seja exagerado; além de muitas vezes levar a conflitos de interesses, sejam interesses reais ou imaginários ${ }^{\mathrm{IX}}$, os quais a psicologia das relações intergrupais mais tarde chamaria de conflitos simbólicos em oposição aos conflitos por recursos materiais (TORRES \& CAMINO, 2013).

Essa lógica "normal" de funcionamento cognitivo nos levaria a construir categoriais para processar ou lidar com a informação social. Nas categorizações, enquadramos elementos ou agregados muitas vezes distintos e díspares em um mesmo "rótulo" de pertencimento (ver Caixa 4).

\section{CAIXA 4 \\ Categorização Social}

É o processo através do qual se reúnem os objetos ou acontecimentos sociais em grupos, que são equivalentes no que diz respeito as ações, intenções e sistemas de crenças do indivíduo (TAJFEL, 1981, pp. 289-90).

A categorização tem cinco funções principais: 1) formar classes ou conjuntos amplos que guiam nossas interações cotidianas; 2) assimilar num mesmo 
rótulo muitos caracteres distintos; 3) reconhecer ou identificar rapidamente um dos seus membros ou elementos; 4) saturar ou contaminar tudo que contém o mesmo "sabor" emocional e ideativo; e 5) funcionar de forma racional ou não (ALLPORT, 1954/1979).

Imagine que você está andando numa rua e vem na sua direção um cão que, ao longe, parece um Pitbull. Você provavelmente acessará sua categoria mental "cães perigosos" e isso orientará suas emoções, pensamentos e comportamentos nos momentos seguintes. O cão se aproxima e você percebe que ele tem feições de um São Bernardo, sendo muito diferente dos Pitbulls que já viu; mas você ainda pensa "deve ser um pitbull misturado" e continua precavido. Neste momento, o cão the olha de um modo que você supõe furioso e você pensa "olhar de pitbull, acertei!". Basta isso, então, para que o pobre e inofensivo São Bernardo passe a ter o mesmo "sabor" e "cheiro" de um Pitbull. Todas essas quatro fases podem ter acontecido sob o seu controle consciente, de forma racional e deliberada, ou podem ter sido ativadas automaticamente, de forma que você nem percebeu quando mudava de calçada e quando se encolheu enquanto cruzava com o cão.

A proposta de Allport, e de outros que estudam os processos de categorização (e.g., ROTHBART \& TAYLOR, 1992), é que essas fases e processos na categorização de objetos naturais são idênticos aos que usamos na categorização de pessoas e grupos humanos, ou seja, objetos sociais (categorização social).

O princípio é o de que nossa mente tende a categorizar os eventos de uma forma grosseira compatível com nossas necessidades imediatistas de ação (ALLPORT, 1979). A essa lógica avara de tratamento da informação se agregaria a tendência à confirmação das expectativas, o que manteria o processo quase imune à realidade. Ou seja, uma vez classificada uma pessoa dentro de um grupo e acessado o estereótipo desse grupo, seria difícil que o comportamento dessa pessoa alterasse esse estado de coisas, pois, cognitivamente, agiríamos, segundo Allport, pela lógica autoconfirmatória do menor esforço.

Importante lembrar que os processos de categorização social não são atividades meramente cognitivas de classificação e organização do mundo em "caixinhas" nas nossas mentes. Tratam-se de ações políticas, marcadas por lutas simbólicas de poder sobre que sentidos e significados dominarão a consciência social acerca de um fenômeno. Como refere Bourdieu (1985), o conhecimento sobre o mundo social e as categorias que o tornam possível são apostas numa luta política, cujo objetivo é conservar ou transformar o "nome social", para assim conservar ou transformar as relações entre as categoriais. 
Pense, por exemplo, no que aconteceu com o nosso país vizinho, a Bolívia, em 2019, quando o presidente Evo Morales renunciou. Como você classificaria o acontecimento: "Golpe de Estado contra a Ordem Democrática" ou "Restauração Constitucional da Ordem Democrática pelos Militares"? Se você é de Direita na política, provavelmente fará uma categorização diferente da de alguém de Esquerda. Os dois certamente construirão emoções, crenças e reações diferentes do fenômeno, motivados pela categorização: "Não é por acaso que o verbo $k a$ tegoresthai, do qual derivam os termos "categorias" e "categoremas", significa acusar publicamente.” (BOURDIEU, 1985, p. 729) ${ }^{\mathrm{X}}$.

O processo mais simplista de categorização leva Allport, citando Spinoza, a propor duas noções para explicar, por um lado, porque podemos amar nosso grupo de forma cega, cheia de preconcepções sobre suas virtudes e, por outro lado, porque podemos odiar o grupo do outro também de forma cega, percebendo somente seus defeitos e ignorando suas virtudes. Trata-se, no primeiro caso, do "love-prejudice" e, no segundo, de "hate-prejudice".

A nossa cultura muitas vezes nos ensina que o amor incondicional ao meu grupo: à minha família, ao meu país, à minha orientação sexual, deve implicar o ódio, o medo ressentido ou o sentimento de ameaça em relação ao outro ou a outra forma de ser. Trata-se de uma lógica binária, na qual a construção de uma identidade positiva passa pela desconstrução e mesmo destruição de outras identificações possíveis. A "masculinidade tóxica" ou masculinidade hegemônica é um bom exemplo de como para amar o que sou preciso odiar o que o outro é (CONNELL \& MESSERSCHMIDT, 2013). Mas será isso inevitável? Será que a categorização social e a identificação com um grupo implicarão sempre no ódio ao diferente?

O próprio Allport tenta responder a esse dilema, afirmando que primeiro aprendemos o amor, os laços iniciais de apego à família são todos de amor; somente depois aprendemos a odiar. Trata-se de uma questão fundamental, pois por trás dela está outra que nos interessa mais ainda: serão os preconceitos inevitáveis?

\subsection{AMOR AO MEU GRUPO E 0 ÓDIO AO DO OUTRO}

Podemos dizer que a reflexão sobre a relação entre amor pelo próprio grupo e ódio pelos outros começa nas ciências sociais com William Graham Sumner (1840-1910). Em 1906, Sumner publica o livro Folkways, no qual tenta explicar costumes e tradições populares que exercem sobre o indivíduo uma coerção para se conformar a eles. Ele introduz a noção do etnocentrismo como 
fato explicativo. $\mathrm{O}$ etnocentrismo é definido como uma visão que implica uma cisão do mundo, na qual o grupo de pertencimento é o centro de tudo, e todos os outros são dimensionados e classificados com referência a ele. Nas palavras de Sumner (1906, pp.15, 18):

Cada grupo nutre seu próprio orgulho e vaidade, se vangloria de sua superioridade, exalta suas próprias divindades e olha com desprezo para quem está de fora. Cada grupo pensa que seus próprios caminhos são os únicos certos, e ao perceber que outros grupos têm outros caminhos, isso excita seu desprezo. Opróbrios são derivados dessas diferenças (p. 15). ${ }^{\mathrm{XI}}$

Todavia, meio século depois de Sumner, Allport (1954) defende que é possível amar o próprio grupo sem odiar o grupo do outro. Dois capítulos de "A natureza do preconceito" são dedicados a essa questão, o capítulo 3, que trata da formação de endogrupos (meu grupo) e o capítulo 4, que se intitula "Rejeição de exogrupos" (grupo do outro). No capítulo 3, Allport começa a discussão enfocando a importância do sentimento de "familiaridade" para a construção da lealdade e do amor aos grupos aos quais pertencemos.

Destaca que, na história da humanidade, a presença de um inimigo comum externo sempre aumentou a coesão e a fidelidade entre os membros de um grupo. No entanto, continua o autor, nenhum pertencimento endogrupal é fixo, os laços variam de cultura para cultura, de época para época e mudam mesmo dentro de uma mesma cultura, pois são diferentes de indivíduo para indivíduo. Um menino de uma determinada família pode definir a sua masculinidade por oposição ao "ser menina", ou seja, de forma conflitiva. Na mesma família, outro menino pode definir sua masculinidade ("endogrupismo") de modo não conflitivo.

O nosso senso de pertencimento é subjetivo e depende da representação mental e social que temos do que são nossos grupos, considerando quem são os membros exemplares e qual o protótipo do grupo (ver Caixa 5). Depende também de como as fronteiras do grupo são traçadas, se com linhas sólidas, que definem claramente os de dentro e os de fora, ou com linhas tracejadas, demarcando limites híbridos e permeáveis. 


\section{CAIXA 5 \\ Protótipos e Exemplares}

A psicologia cognitiva nos ensina que no processamento categorizamos os objetos em função de suas características e/ou da nossa motivação. Nesse processo, podemos recorrer à categorização em função de exemplares e de protótipos. No caso do protótipo o conhecimento sobre a categoria é armazenado em termos de atributos que sejam a "melhor" instância representativa de uma categoria. Por exemplo, a representação mental da categoria GATOS coincide com um gato prototípico: animal peludo, de quatro patas, e garras retráteis, que miam e ronronam. Já na informação do tipo exemplar, a categoria é representada como um conjunto de exemplos específicos armazenados na memória. Neste caso, a representação mental do conceito GATO é o conjunto de representações dos gatos que encontramos durante nossa vida, por exemplo o Frajola (FRIXIONE \& LIETO, 2013).

Um terceiro plano importante de análise, para entender a origem do preconceito, tem a ver com o campo relacional dos grupos. Nesse plano, deve-se considerar quê outros grupos são referência para a construção identitária do nosso grupo e quê grupos são oposição para tal. A esse respeito, é importante ter em conta o campo das relações de poder e a consequente noção de grupo maioritário e minoritário (ver Caixa 6). Nesse sentido, Allport apresenta a tese de que são as normas dos endogrupos que definem o tipo de "belongingness" (pertencimento) que seus membros adotarão, se mais excludente e preconceituoso, ou mais inclusivo e não preconceituoso:

Por causa de sua importância básica para a nossa sobrevivência e autoestima nós tendemos a desenvolver partidarismo e etnocentrismo em relação aos endogrupos. (...) Assim, ainda que uma certa predileção pelos membros do próprio grupo possa ser inevitável, o sentimento pelos membros de outros grupos pode variar muito. Num extremo, eles podem ser vistos como inimigo comum a ser vencido para proteger o endogrupo. No outro extremo, o exogrupo pode ser valorizado, tolerado e até mesmo amado por sua diversidade. (ALLPORT, 1979, p. 42)

\section{CAIXA 6 \\ Maioria e minoria social}

Na psicologia social esses termos não se relacionam com o tamanho numérico dos grupos, mas às suas posições de poder sociorreligiosas, sociopolíticas, socioeconômicas e sociodemográficas. Os termos maioria e minoria também se referem a condições, tratamento e status sociais positivos ou negativos. Minoria se refere a grupos negativamente denotados (estigmatizados, segregados, oprimidos e marginalizados). Enquanto a maioria denota grupos de status com valor positivo (ver SEYRANIAN, ATUEL, \& CRANO, 2008). 
Numa direção diferente de Allport e alinhada à de Sumner, Henri Tajfel (1981) (ver Caixa 7) formula sua Teoria da Identidade Social (TIS), a qual também traz uma explicação para o preconceito. A questão proposta por Tajfel era a de entender como é possível o genocídio. Seus estudos começam em 1968, na Inglaterra. O pressuposto básico da TIS é o de que o preconceito, que muitas vezes conduz e legitima os genocídios, é um processo racional, que se inicia num simples ato, a categorização de pessoas diferentes em diferentes grupos (BILLIG, 1992). As evidências de pesquisa decorrem de um paradigma conhecido na psicologia social como "Paradigma dos Grupos Mínimos".

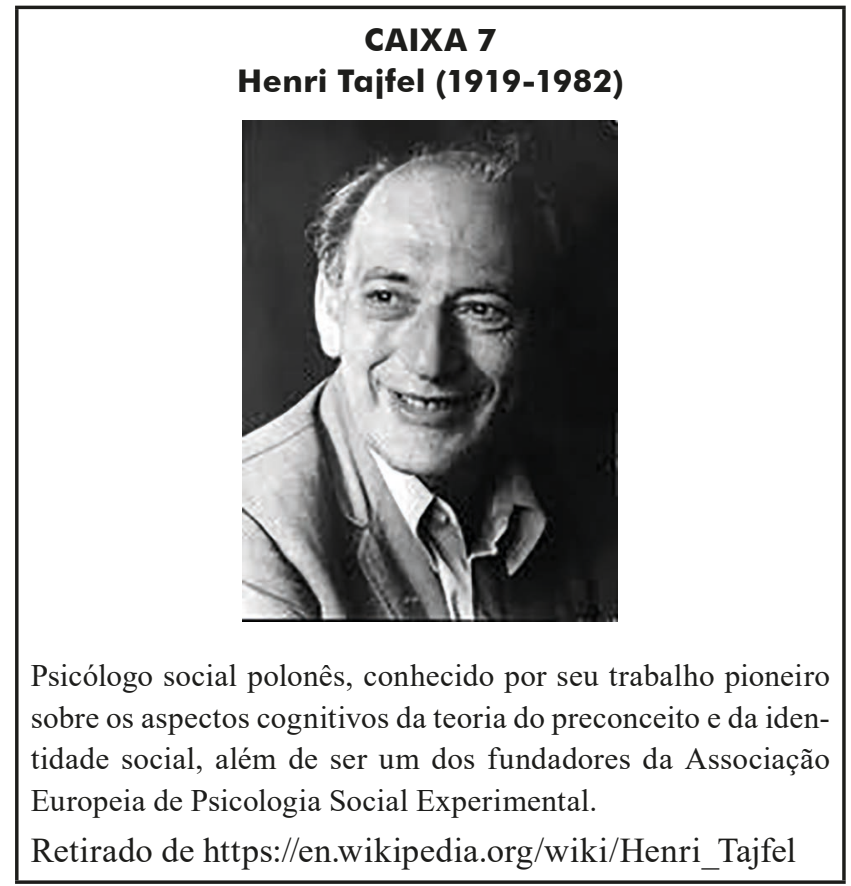

Tajfel, Billig, Bundy e Flament (1971), em dois experimentos, pediam que 48 rapazes com idades entre 15 a 16 anos indicassem suas preferências estéticas escolhendo pinturas apresentadas em 12 slides coloridos. As pinturas eram de dois pintores abstratos (Klee e Kandinsky). Com base nessas preferências, os jovens eram divididos em dois grupos: o grupo dos que preferiram a mesma pintura que eles (Grupo Klee) e o grupo que preferiu a outra pintura (Grupo Kandinsky). Em seguida, em uma série de matrizes numéricas, os rapazes deveriam dividir dinheiro entre membros dos dois grupos. Importante referir que as entrevistas eram individuais, que os participantes nunca tiveram uma interação 
com os outros e que a própria divisão em grupos foi aleatória. Ou seja, eles alocavam dinheiro para outros que eram anônimos, sabendo apenas se eram do Grupo Klee ou Kandinsky. Na Figura 3, podemos ver uma das várias matrizes utilizadas no estudo de Tajfel e cols. (1971), nela, circulamos as três escolhas mais comuns dos adolescentes pesquisados. E você, qual delas escolheria, considerando ser o seu grupo o Klee?

Figura 3: Matriz utilizada no Paradigma dos Grupos Mínimos (Matriz 3, tipo B, Exp. 2)

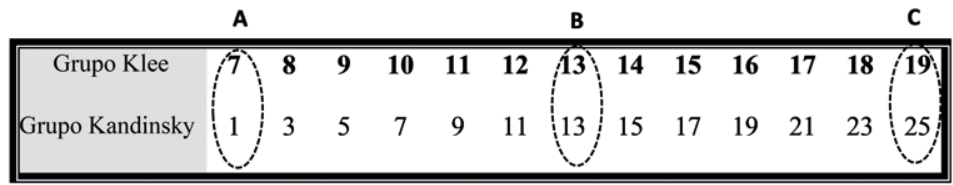

Em muitas variações de matrizes, Tajfel e cols. (1971) observam que 72\% dos rapazes favorecem membros do seu grupo na distribuição e apenas 19\% favorecem o exogrupo. Os 9\% restantes foram igualitários. No segundo experimento, foram analisadas três situações: 1) MGC (Máximo Ganho Conjunto), equivalente à escolha em uma matriz que resulta no maior benefício comum possível para os dois indivíduos dos dois grupos (Letra B na Fig. 3); 2) MGE (Máximo Ganho Endogrupal) definido como a escolha em uma matriz que corresponde ao maior ganho absoluto para um membro do endogrupo (Letra $\mathrm{C}$ na Fig. 3); e 3) MDI (Máxima Diferença Intergrupal) definida como a escolha que resulta na maior diferença possível entre os ganhos a favor do membro do endogrupo (Letra A na Fig. 3). Os rapazes escolhem mais a alternativa representada pela letra "A" que a "B" e a "C" somadas. Ou seja, eles preferem "ganhar" apenas 7 para dar somente 1 .

Tajfel (1981) formula a Teoria da Identidade Social para explicar esse fenômeno e propõe que preconceito repousa sobre quatro elementos interligados: categorização social, identidade social, comparação social e distintividade psicológica (TAJFEL \& TURNER, 1979). Nessa perspectiva, só existe preconceito porque: i) dividimos o mundo social em categorias ou grupos - o nosso grupo versus o grupo dos outros; ii) tendemos a preferir o nosso grupo mesmo em situações sociais aparentemente neutras, como as do Paradigma dos Grupos Mínimos; iii) comparamos nosso grupo com o grupo dos outros o que afeta a nossa autoestima e iv) maximizamos as diferenças entre o nosso grupo e o grupo dos outros e minimizamos as diferenças internas aos grupos. Em linhas gerais, essa é a explicação da TIS para o preconceito e os genocídios que ele pode produzir. 
É mesmo impressionante que uma preferência por quadros de pintores de mesmo estilo, que visualmente não se distinguem em nada importante, possa gerar comportamentos de discriminação contra outros que nunca vimos ou veremos. Mas será assim na vida real? Ou seja, alguma vez tratamos alguém mal por causa de uma preferência do tipo "eu gosto mais dos que gostam do verde do que dos que gostam do azul'?

Nossas vidas são marcadas, na maior parte do tempo, por conflitos que decorrem de escolhas e pertencimentos cuja relevância desapareceria no máximo em 30 segundos de análise desapaixonada, contextos "mínimos" no sentido de Tajfel (1981). Todavia, como nos lembra Pierre Bourdieu (2007), os gostos e preferências distinguem classes de pessoas e posições na estrutura social; sendo a percepção de ameaça simbólica, - à cultura ou valores que estruturam esses "gostos", que está na base da maior parte das chamadas "novas expressões de preconceito", assunto sobre o qual falaremos mais à frente.

Você deve estar confuso, uma parte da psicologia social do preconceito diz que o amor ao próprio grupo não implica ódio ao grupo do outro, a outra diz que só sabemos amar odiando. E agora! Em quem acreditar? O que acha, considerando seus pertencimentos sociais? Digamos que você seja brasileiro, de sexo masculino, heterossexual, católico e tenha a pele branca. Você acha que sua identificação com essas categorias sociais implica em preconceito contra os não brasileiros, as mulheres, os homossexuais, os não católicos e os não brancos? Acha que quanto mais desvaloriza cada um desses pertencimentos que não são seus, mais gosta dos seus? Não responda ainda!

Marilynn Brewer, uma psicóloga social norte-americana, escreveu em 1999, um texto clássico para tentar dar conta dessa questão: "A psicologia do preconceito: amor ao meu grupo ou ódio ao grupo do outro?”. A ideia central da autora é de que o favorecimento do endogrupo é geralmente independente da desvalorização do exogrupo. Mas há condições em que um implica o outro. Segundo ela, a luta entre duas motivações evolutivas definirá a direção da relação, se de amor ou de ódio pelos membros do exogrupo. Uma seria a motivação para a inclusão ou assimilação dos outros, que geralmente surge quando estamos em situação de isolamento e precisamos da proteção ou ajuda. A outra motivação, referente à necessidade de_diferenciação dos outros, surge em situações opostas, quando estamos imersos em coletividades amplas e amorfas, as quais nos levam a buscar uma distinção em relação aos outros. $\mathrm{O}$ equilíbrio entre os motivos de diferenciação e de inclusão pode ser alcançado pelo pertencimento a grupos ou categoriais sociais que possuem objetivos percebidos 
como comuns ou compatíveis, num plano mais amplo (superordenado) de comparação social (BREWER, 1999).

Vamos supor que eu me identifique politicamente como sendo de "direita" e que você se identifique como sendo de "esquerda". Mas que ambos queiramos um país mais justo, sem corrupção e mais eficiente no gasto e na qualidade dos serviços públicos. Nesse sentido ideal, é possível que a minha identificação social como "direitista" não seja construída e nem se faça derivar do ódio à sua condição identitária de "esquerdista". Num plano imaginário de inserções sociais, haveria um círculo concêntrico que nos uniria: o do pertencimento a uma categoria social superordenada (mais ampla e inclusiva), que poderíamos chamar de "cidadão brasileiro responsável e bem-intencionado". Nesse plano, nossas necessidades de inclusão numa categoria social, de lealdade a ela e de diferenciação em relação à outra categoria (Esquerda versus Direita no nosso exemplo) não implicam em conflito de interesses e em ódio ou menosprezo pelo outro diferente.

No entanto, como sabemos, há uma série de contextos em que o desfecho da relação com a diferença é menos feliz. Brewer (1999) refere cinco situações nas quais manter a identificação a um grupo ou categoria implica em hostilidade e mesmo ódio ao exogrupo: 1) superioridade moral; 2) percepção de ameaça; 3) interesses conflitantes comuns; 4) valores e níveis de comparação social comuns; e 5) políticas de poder.

Voltemos ao nosso exemplo, eu enquanto alguém identificado com a direita política, posso supor que você, "um esquerdista", não pertence à mesma comunidade moral que eu, e, portanto, não adota os princípios éticos corretos: "você não valoriza o combate a corrupção da mesma forma que eu valorizo". De forma que a minha suposta "superioridade moral" conduz a um tipo de escalada na qual quanto mais eu me identifico como sendo de direita, mais lhe identifico como de esquerda, mais raiva sinto de você e de todos os outros como você. Tal menosprezo se amplificará ainda mais se estivermos num contexto de ameaça, de competição por recursos ou pelo poder político. Nesse cenário, perceber que lutamos pelos mesmos objetivos, por exemplo, alcançar o poder político ou manter alguém da nossa "facção" nele, pode também ampliar o conflito e o ódio entre o meu e o seu grupo. Nessas circunstâncias, podemos dizer que o "caldo azedou" e quando o caldo azeda até açúcar vira sal.

Nesses termos, perceber que membros do outro grupo com o qual estamos em litígio partilham valores iguais aos dos nosso grupo, aumenta nossa necessidade de diferenciação, de distintividade positiva. Trata-se de algo como, "não 
sou apenas diferente de você e dos outros iguais a você, sou melhor, superior!”. Finalmente, tudo isso ocorre numa arena de políticas de poder, na qual líderes ou figuras de influência manipulam informações para, polarizando mais e mais os grupos, manter e aumentar o seu poder na estrutura social.

No nosso exemplo da Esquerda vs. Direita, basta imaginar a quantidade de mensagens que algum aplicativo de redes sociais poderia nos enviar promovendo a forma de ser do nosso grupo e depreciando a do grupo do outro. Na fase final desse processo, teríamos uma sociedade irreconciliavelmente dividida, em "coxinhas" e "mortadelas", de uma forma tão intensa e polarizada que a afirmação de uma identidade terá sempre como consequência o menosprezo da outra, a ponto de surgirem propostas de extermínio da diferença.

Todavia, a intersecção de múltiplos pertencimentos a grupos cria elevada distintividade entre os indivíduos, permitindo acesso e adoção de sistemas de crenças e valores diversos, tornando complexo e diferenciado o modo como cada um vivencia seus pertencimentos e reage à diferença (BREWER, 1999).

O fato concreto é que, como nos ensina a Teoria da Identidade Social de Tajfel (1981), independentemente das diferenças individuais, haverá por parte da sociedade uma pressão para a minimização das diferenças internas às categorias ou grupos e para a ampliação das diferenças entre eles, tornando difícil a vida social para todos, com ofensas generalizadoras e outras agressões de ambos os lados. Isso cria um contexto de relações no qual o simples fato de o outro existir já é sentido como ameaça.

Vamos agora tentar aprofundar um pouco mais o efeito da percepção e ameaça nos preconceitos.

\subsection{A PERCEPÇÃO DE AMEAC̦A E AS EXPRESSÕES DE PRECONCEITO}

Imagine que você está fazendo pós-graduação numa universidade pública do Brasil. Você é branco e tem um colega negro, você é progressista do ponto de vista político e ele conservador, ambos possuem bolsa de pós-graduação: ele é cotista racial e você não. No intervalo de uma aula vocês iniciam uma discussão acalorada sobre a "Escola sem partido". Ele defende o fim das ideologias no ensino e você acha que isso ameaçaria o pensamento crítico dos alunos. Vocês se aferram às suas posições e a discussão começa a ganhar ares de conflito intergrupal, no qual o modo de pensar do colega (conservador) ameaça o seu (progressista). Enquanto vocês discutem o Governo Federal resolve cortar novamente 5 mil bolsas de Mestrado. Vocês recebem pelo celular uma mensagem da 
coordenação do Programa informando que com o corte talvez apenas as bolsas dos cotistas sejam mantidas. Antes da mensagem chegar podemos dizer que a discussão entre vocês se dava numa arena das percepções de ameaças simbólicas, às formas de pensar. Depois da mensagem, a discussão, e mais importante, a percepção do outro, pode adentrar o campo das percepções de ameaças reais/ materiais, inclusive "balançando" sua posição mais "progressista".

Na psicologia social, a teoria que procura explicar o efeito dessas percepções de ameaça no preconceito é a Teoria Integrada da Ameaça (Integrated Threat Theory) proposta por Stephan e Stephan (2000). A ideia central dessa teoria é a de que os membros das minorias sociais vivem sempre em um tipo de "cerco" na sociedade, sitiados em contextos de relações intergrupais que desencadeiam quatro tipos de percepções/sentimentos: a ameaça real, a ameaça simbólica, a ansiedade intergrupal e os estereótipos negativos (ver Figura 4).

Figura 4: Modelo da Teoria Integrada da Ameaça

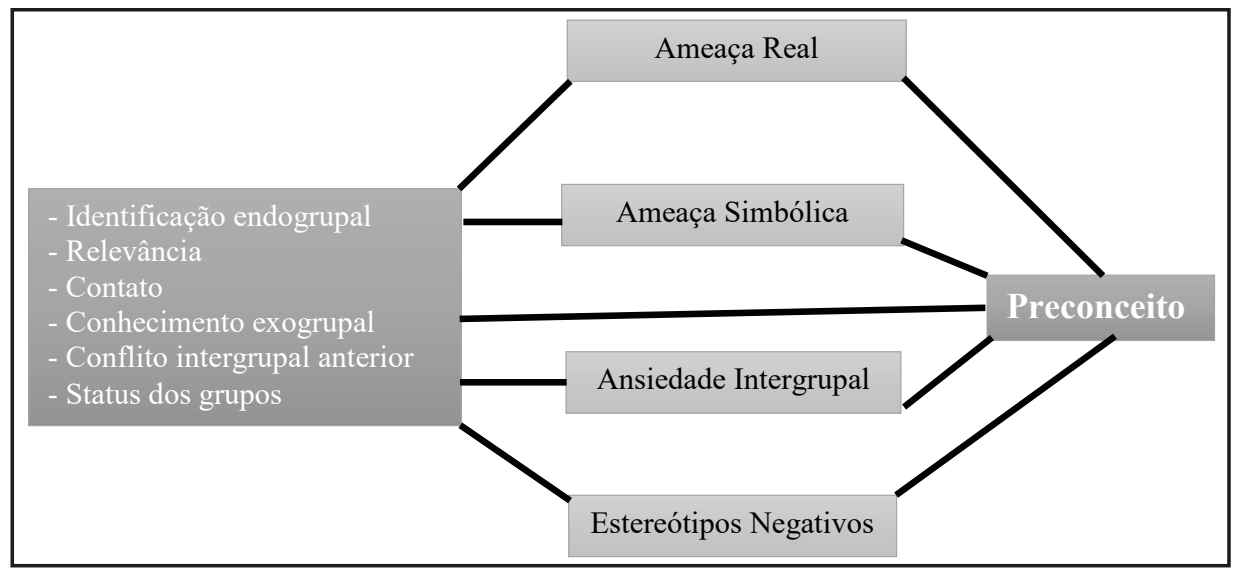

(Extraído de STEPHAN \& STEPHAN, 2000, p. 37)

A ameaça real decorre das teorias do conflito realístico que veremos mais à frente, nela, predominam as preocupações com danos físicos, segurança ou perda de recursos materiais, como perder uma bolsa de Mestrado, ou o emprego. As formas mais abertas de preconceito se expressam muitas vezes motivadas por essa modalidade de ameaça. No caso do sexismo, por exemplo, quando as mulheres começam a ocupar espaços antes exclusivamente masculinos, podem surgir ou ressurgir formas mais tradicionais e abertas de preconceito, o chamado "sexismo hostil" (GLICK \& FISKE, 1996). Da mesma forma, quando considera que os imigrantes ameaçam os empregos e a 
segurança dos "nativos", o preconceito flagrante se manifesta (PETTIGREW \& MEERTENS, 1995).

A ameaça simbólica se refere à preocupação com a integridade ou validade do sistema de significados e valores. Ou seja, decorre da percepção de que o outro pode invalidar ou "contaminar" as visões de mundo do meu grupo, da minha cultura (STEPHAN \& STEPHAN, 2000). Essa percepção estrutura aquilo que a literatura psicossocial chama de "novas formas" de preconceito (ver LIMA \& VALA 2004b). Estas novas expressões recebem diversos nomes e diferem em função das peculiaridades dos seus contextos de manifestação e das minorias alvo do preconceito. No caso do preconceito racial, temos o chamado racismo "Simbólico" ou o "Moderno" que se caracteriza pela crença de que os negros violam os valores tradicionais do individualismo e da meritocracia (KINDER \& SEARS, 1981). Ou seja, os negros seriam vistos como não sendo autodisciplinados e não se esforçando o suficente. Já a teoria do preconceito "sutil" propõe que as atitudes contra certas minorias culturais decorrem da defesa dos valores tradicionais, baseando-se na percepção de que eles são muito diferentes dos membros do meu grupo e ameaçam a centralidade e até a universalidade dos nossos valores (PETTIGREW \& MEERTENS, 1995). Em relação ao sexismo, a ameaça simbólica estrutura a expressão chamada de "benevolente". O sexista benevolvente é aquele que percebe a mulher como um complemento ao homem, a "cara-metade", supondo que ela necessita da proteção masculina por ser frágil e dependente (GLICK \& FISKE, 1996; CONNOR, GLICK, \& FISKE, 2018). Em relação à homofobia, a ameaça simbólica se estrutura no "Heterossexismo", definido como um sistema de diferenciação cultural, que exclui as identidades, comportamentos, relações e comunidades não heterossexuais (HEREK, 2008). A homofobia derivaria da percepção de que os homossexuais manifestam preferências ou orientações que ameaçam os valores da cultura heterossexista.

A ansiedade intergrupal, terceiro tipo de ameaça destacada na teoria, se refere ao estado de desconforto emocional que as interações intergrupais geram. Emoções como o medo de ser rejeitado ou o embaraço de se mostrar preconceituoso. A ansiedade presente nesses encontros ajudaria a alimentar o preconceito. Em relação aos encontros com membros de outros "grupos raciais", merece destaque a teoria do racismo aversivo, que propõe que haveria um conflito entre crenças associadas a valores igualitários com emoções de desconforto, nervosismo, ansiedade e algumas vezes medo nos encontros entre brancos e negros (DOVIDIO \& GAERTNER, 1998). Também se pode pensar o preconceito contra outras minorias com base na noção de ansiedade. Boa parte 
das atitudes homofóbicas decorrem da crença de que os gays são sexualmente descontrolados. Numa pesquisa sobre o modo como evangélicos conservadores do Brasil veem os LGBTs, encontra-se a seguinte imagem: "Este sujeito ameaçador encarna distintos personagens: ele seria pedófilo, agressivo, amoral, descontrolado, sujo, contaminador/propagador de doenças, abusador sexual, possuído por demônios, instrumento do Enganador (satã)" (NATIVIDADE \& DE OLIVEIRA, 2009, p. 154). Outros estudos encontram associações da homofobia com o nojo (TAPIAS, GLASE, KELTNER, VASQUEZ, \& WICKENS, 2007). O preconceito contra as pessoas em sofrimento psíquico, os "loucos", também é, em larga medida, estruturado pela ansiedade intergrupal; a percepção de que eles são incontroláveis, imprevisíveis e agressivos estrutura as atitudes negativas e de isolamento por parte da maioria dita "normal" (MACIEL, VIEIRA, SOUSA, LIMA, \& RIBEIRO, 2019).

Os estereótipos muitas vezes geram expectativas negativas em relação ao comportamento dos membros dos grupos minoritários. Os estereótipos negativos são, portanto, a quarta ameaça proposta no modelo de Stephan e Stephan (2000). Em relação ao preconceito de gênero, ocorre uma diferenciação nos estereótipos de homens e mulheres, sendo os homens mais descritos em termos de características positivas de instrumentalidade para a realização de tarefas (e.g., independentes, assertivos, autossuficientes etc.) que as mulheres (FISKE, CUDDY, \& GLICK, 2002). O mesmo padrão de estereotipia acontece contra outras minorias quando contrastadas com a maioria, a exemplo de pessoas com deficiência (FISKE et al., 2002), idosos (DE PAULA COUTO \& KOLLER, 2012) e nordestinos (TECHIO, 2011). No caso do preconceito racial, uma das teorias mais importantes, a do racismo ambivalente, propõe que essa ambivalência estrutura dois tipos de atitudes, as atitudes pró e anti-Negros. As atitudes anti se baseiam em traços negativos dos estereótipos dos negros, tais como: "falta de disciplina", "desorganização", "preguiça", "superstição" (KATZ \& HASS, 1988). Em relação ao preconceito contra idosos, Vieira e Lima (2015) encontram que os estereótipos mais aplicados a eles foram negativos: "inúteis", "incapazes" e "estorvo".

$\mathrm{Na}$ atualidade, vivemos, e cada vez mais intensamente, num mundo polarizado, dividido em múltiplos pertencimentos. Podemos pertencer a uma religião, pertencemos a uma nacionalidade, professamos uma ideologia política, preferimos uma orientação sexual, pertencemos a uma etnia, e assim segue. Quase todas essas posições de sujeito estão permeadas por conflitos, gerando sensações ou percepções de ameaça, real ou simbólica, ansiedades e imagens que azedam 
as relações. Nesse sentido, o modelo proposto por Stephan e Stephan (2000) é poderoso ao demonstrar a importância da percepção de ameaça na explicação de várias formas de expressão do preconceito, desde as mais sutis ou disfarçadas, às mais abertas ou flagrantes (ver PEREIRA, VALA, \& LEYENS, 2009). Todavia, há limitações importantes no modelo que precisamos destacar.

A maior parte das atuais "novas expressões" de preconceito refletem um fenômeno denominado de assimetria positivo/negativo (MUMMENDEY, 1995). Vários estudos verificam esse fenômeno, definido como uma menor atribuição de traços estereotípicos positivos às minorias sociais quando comparadas às maiorias, acompanhada da não diferenciação na atribuição de traços negativos (e.g., GAERTNER \& MCLAUGHLIN, 1983; PETTIGREW \& MEERTENS, 1995). É como se a norma social antipreconceito conduzisse a expressões mais "sutis": "Eles não são piores que nós, mas nós somos melhores que eles" (VALA, BRITO, \& LOPES, 1999).

Estando a estereotipia negativa em certo desuso nas novas expressões de preconceito, passa a ser muito importante analisar como o conteúdo dos estereótipos interfere no preconceito. Esse é outro elemento fundamental negligenciado no Modelo da Ameaça Integrada.

Alguns estudos demonstram que, em termos de conteúdo, são atribuídos mais traços estereotípicos de "cultura positiva" (e.g., solidários, leais) para descrever os brancos ou os não ciganos e mais caracteres de "natureza positiva" (e.g., alegres, intuitivos) para descrever negros e ciganos (LIMA \& VALA, 2004c; MOSCOVICI \& PEREZ, 1999). Resultados que configuram um tipo de desumanização das minorias. Outros estudos verificam que o sexismo pode se estruturar por uma maior atribuição às mulheres que aos homens de estereótipos referentes à competência emocional (e.g., sensíveis, prestativas, afetivas etc.) (FISKE, CUDDY, \& GLICK, 2002). Resultados semelhantes são encontrados nas descrições de pessoas com deficiência (FISKE et al., 2002), de idosos (DE PAULA COUTO \& KOLLER, 2012) e de nordestinos (TECHIO, 2011).

Finalmente, na dimensão de ansiedade intergrupal do modelo de Stephan e Stephan (2000), falta acrescentar que muitas vezes a infra-humanização do outro minoritário pode ser feita não somente através das emoções negativas, mas também através de emoções positivas e pela negação da capacidade de expressar sentimentos ou emoções secundárias, aquelas que são cognitivamente mais complexas. Assim, não apenas ansiedade, raiva e medo estão na origem dos preconceitos. Evidências demonstram que emoções positivas como a pena se relacionam ao preconceito contra idosos e pessoas com deficiência (FISKE et al., 
2002), e com a homofobia que associa gays a Aids (COTTRELL \& NEUBERG, 2005). Por outro lado, no campo das percepções do outro, eles (minorias) ameaçam não somente porque despertam medo e ansiedade, mas porque são menos capazes de sentir, por exemplo, compaixão e empatia (LEYENS et al., 2000; LEYENS et al., 2001).

Não obstante os limites apontados, a Teoria Integrada da Ameaça é um modelo explicativo muito importante, pois enfatiza um elemento fundamental na produção do preconceito: a ameaça. A ameaça altera as formas de expressão do preconceito, quando ela está ausente, ele pode se manter mais "calado", "sutil" e "frio", quando ela surge, o "monstro" acorda e urra. Em contextos de conflito nas relações intergrupo, de luta por recursos escassos, a ameaça real produz um tipo de preconceito que, por ser mais abertamente violento, merece um destaque mais aprofundado.

\subsubsection{Competição por recursos materiais, ameaça e preconceito}

Quando os recursos materiais são limitados, haverá competição por eles, alimentando a exploração de um grupo sobre outro, e o preconceito. Há sólida evidência de que os níveis de preconceito aumentam quando ocorrem crises que produzem escasseamento de empregos e outros recursos materiais (ver ARONSON, 1999; BOBO, 1988 para revisões). Agora mesmo, enquanto escrevo esse texto, estamos vivendo a pandemia do Coronavírus, que aumentou significativamente a xenofobia contra os chineses.

Na primeira metade do século XX, a psicologia formulou e testou uma hipótese que vinculava conflito intergrupos e recessão econômica. Esta hipótese, que ficou conhecida como Frustração-Agressão, foi proposta por Dollard, Doob, Miller, Mowrer e Sears (1939), sendo empiricamente testada por Hovland e Sears em 1940. Os autores propõem que as frustrações decorrentes das crises econômicas produzem impulsos agressivos que serão direcionados a alvos vulneráveis, tais como minorias sociais. Trata-se aqui da tese do "bode expiatório", aquele que será imolado em nome das nossas culpas, como ilustrado de forma caricata na Figura 5.

Analisando a relação entre a crise econômica no Sul dos Estados Unidos e a frequência de linchamentos de cidadãos negros, Hovland e Sears (1940) concluíram que havia forte associação estatística entre a queda dos preços do algodão e o aumento dos linchamentos. Muitas críticas foram feitas aos dados e análises desses autores, e mais recentemente algumas reanálises foram conduzidas. Essas novas análises verificam que existe sim uma relação entre depressão econômica 
e violência contra minorias étnicas, mas ela é mais fraca que a verificada no estudo original (ver GREEN, GLASER, \& RICH, 1998).

Figura 5: A frustração-agressão e o "bode expiatório"

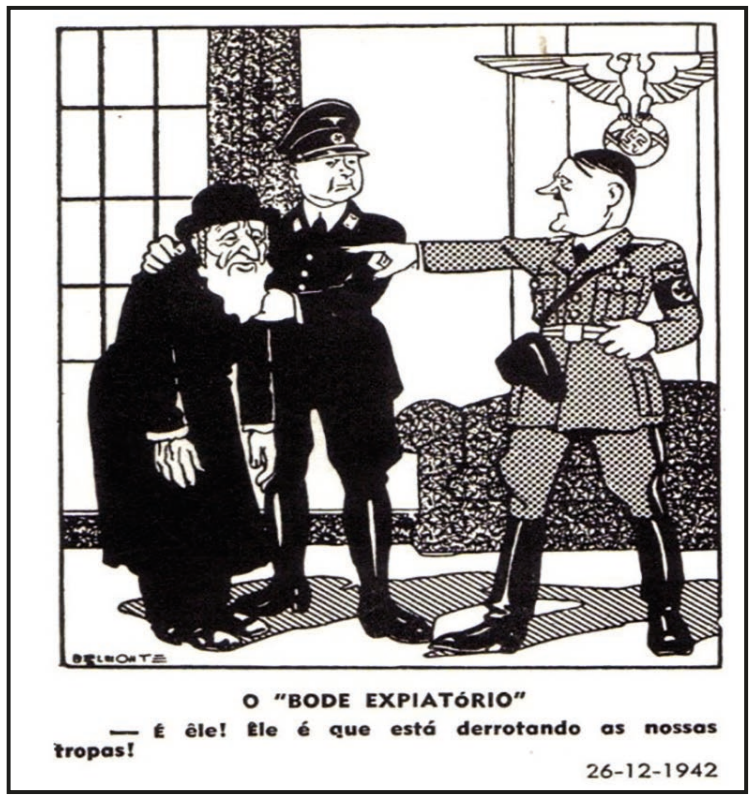

(Retirada de https://ensinarhistoriajoelza.com.br/belmonte-o-caricaturista-queirritou-goebbels/guerra_hitler_-bode-expiatorio26-12-42/)

Provavelmente, a mais famosa evidência dos efeitos da luta por recursos no conflito intergrupos e no preconceito que dele resulta advém dos estudos conhecidos como "A Experiência da Caverna dos Ladrões", conduzidos por Muzafer Sherif (ver Caixa 8) na década de 1950, na colônia de férias Robbers Cave, em Oklahoma. Os participantes da experiência foram 24 meninos de 12 anos de idade, pertencentes a famílias protestantes de classe média dos EUA. $\mathrm{O}$ estudo foi realizado em três fases. $\mathrm{Na}$ fase 1, foram criados os grupos com estrutura hierárquica e conjunto de normas, através da introdução de metas de desempenho e problemas que fizessem os meninos trabalharem conjuntamente para resolver. Na fase 2, os dois grupos formados, as "Águias" (Eagles) e os "Cascáveis" (Rattlers), foram expostos a situações de competição por determinados objetivos em condições que implicavam frustração e tensão entre eles. Na fase 3, foram introduzidos objetivos supraordenados, aqueles que, para serem alcançados, demandavam a cooperação dos dois grupos. 


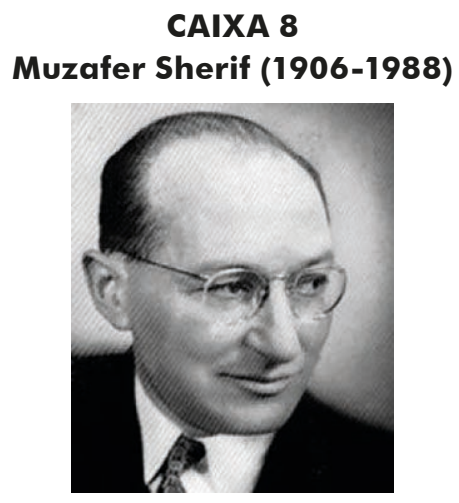

Psicólogo social turco que ajudou a desenvolver a teoria do julgamento social e a teoria realista dos conflitos. Considerado um dos fundadores da moderna psicologia social, pois desenvolveu várias técnicas para entender os processos sociais em grupo, particularmente as normas sociais e os conflitos sociais.

Retirado de https://en.wikipedia.org/wiki/Muzafer_Sherif

Na fase 2, Sherif e colaboradores verificaram que as crianças do grupo das "Águias" escolheram membros do seu grupo em 92,5\% das vezes para interações afetivamente próximas; enquanto os "Cascáveis" escolheram outros “Cascáveis" em 93,6\%. Também no nível dos estereótipos, os autores observaram uma atribuição de traços completamente favoráveis ao endogrupo e a atribuição de traços desfavoráveis ao exogrupo. Além disso, vários comportamentos expressos em slogans depreciativos e invasões de barracas demonstraram a hostilidade intergrupal:

Atitudes claramente negativas e distância social em relação ao grupo externo foram expressas pelos dois grupos. Esses atritos entre grupos também se manifestaram naquele momento por meio de julgamentos de desempenho e expressões de estereótipo."XIII (SHERIF, HARVEY, WHITE, HOOD, \& SHERIF, 1954/1961, p. 112).

\subsection{FATORES INDIVIDUAIS NO PRECONCEITO: "CADA CABECCA UMA SENTENC̦A!"}

Durante a leitura desse texto, enquanto tentávamos explicar o porquê de as pessoas expressarem preconceito, provavelmente você pensou ou pelo menos pensou em pensar algo como: “eu agiria diferente!". Os autores deste livro e toda a psicologia social acreditam piamente em você, tanto que foram formuladas várias explicações para o preconceito num plano mais individual, para demonstrar que existem grandes diferenças entre as pessoas nesse domínio. 
Até então, vimos várias explicações para a existência dos preconceitos, a maior parte delas focada nos contextos de relações, nas ameaças percebidas e nas imagens construídas sobre os grupos. No entanto, sabemos que as pessoas são diferentes, e que, mesmo em contextos muito similares de socialização, haverá formas de pensar e reagir bastante distintas. Isso aponta para a importância dos fatores mais individuais ou de personalidade nas explicações para o preconceito. Destacaremos duas das mais importantes explicações para o preconceito em termos da personalidade: a Teoria da Personalidade Autoritária e a Teoria da Dominância Social. Seguiremos, nesta parte do texto, o capítulo de Lima (2013), no qual o leitor interessado poderá ter acesso a informações mais aprofundadas incluindo as críticas e limites de cada explicação.

O preconceito é a expressão de uma necessidade interna gerada por uma personalidade patológica formatada na primeira infância. Essa é a ideia central da Teoria da Personalidade Autoritária (TPA) formulada na Escola de Frankfurt nos anos 50 do século passado. A TPA surgiu no cenário pós Segunda Guerra e procurava entender porque tantos aderiram aos apelos do nazifascismo. Essa teoria propõe que somente indivíduos com disfunções ou distúrbios de personalidade poderiam tolerar ou participar das atrocidades do nazismo, mas que esses "distúrbios de personalidade" eram socialmente produzidos e "normalizados" em larga escala nas famílias alemãs.

Theodor Adorno e colaboradores, os pais da TPA, fizeram uma pesquisa com mais de 2000 pessoas de diferentes segmentos sociais nos Estados Unidos, o questionário era composto por medidas de antissemitismo, autoritarismo e racismo. Numa segunda fase do estudo, os 150 participantes com escores extremos nas escalas, isto é, os mais e os menos preconceituosos, foram chamados para "entrevistas psicanalíticas". Nessa fase, se verificou que nas narrativas dos mais autoritários eram recorrentes as experiências infantis de socialização com pais severos, que, entretanto, eram admirados de forma excessiva e não crítica. Havia nas falas um sentimento ambivalente de ter sido vítima de uma tirania junto com o de idealização da figura paterna. Essas experiências infantis de socialização criariam um "estilo cognitivo" que a pessoa carregaria na sua vida adulta. Tal estilo seria alimentado pelo mecanismo psicológico da repressão de todos os desejos que pudessem gerar vergonha e culpa. Para descarregar esses afetos "vergonhosos", o indivíduo com personalidade autoritária escolheria "bodes expiatórios", construindo via projeção (outro mecanismo psicanalítico) uma imagem de que os outros são pecadores, descontrolados sexualmente, pervertidos, ou seja, culpados das próprias culpas que corroíam a personalidade doentia do autoritário. 
Esse quadro clínico da TPA recebeu pinceladas finais de Erich Fromm, no livro "O medo da liberdade". Fromm afirma que tal personalidade, por ser incapaz de estabelecer autênticas relações íntimas, se vincula ao mundo de forma artificial, construindo figuras míticas e heroicas, objetos de cultos e figurações (fantasias) de inimigos ou traidores (BILLIG, 1984). Tais características seriam impressas na criança desde o início da infância, constituindo a "personalidade autoritária", de forma que, quando adulta, seria suscetível a aceitar os apelos do preconceito e do fascismo (ADORNO, FRENKEL-BRUNSWIK, LEVINSON, \& SANFORD, 1950).

Friedrich Nietzsche (1844-1900), filósofo alemão, também nos ajuda a entender a origem dos preconceitos. Ele afirmava que a vontade de poder é um impulso fundamental e não racional da vida humana: "A vida, como caso particular, aspira ao máximo sentimento de potência possível. Aspirar a outra coisa não é senão aspirar à potência." (ABBAGNANO, 2007, p. 1009). Essa vontade de poder pode se constituir como um princípio de dominação do outro que está na base do preconceito. Surge, então, uma teoria com esses postulados, a Teoria da Dominância Social (TDS). Ela afirma que temos uma motivação básica para dominar os outros, a qual estrutura hierarquias e se opõe à igualdade. A orientação para a dominação leva "ao desejo do indivíduo de que seu grupo domine o outro grupo e que dentro do seu grupo ele ou ela domine os outros membros" (SIDANIUS, PRATTO, \& BOBO, 1996, p. 1000) XIV $^{\text {. }}$

A TDS propõe a existência de três grandes sistemas de hierarquias de grupos humanos. O primeiro sistema é da idade. Na maior parte das culturas, aqueles considerados "adultos" desfrutam de mais poder social, político e econômico que os considerados "juvenis". O segundo sistema de hierarquia grupal é o do patriarcado. Na maior parte das sociedades, os homens têm mais poder que as mulheres, embora isso varie de cultura para cultura e de época para época. Finalmente, a terceira dimensão de hierarquia grupal é chamada "arbitrária", ela emerge no quadro de relações de poder mais contextuais e históricas, presentes em relações como heterossexuais vs. homossexuais, brancos vs. negros, dentre outras (SIDANIUS, COTTERILL, SHEEHY-SKEFFINGTON, KTEILY, \& CARVACHO, 2018). Essa explicação se associa à teoria do "senso de posição grupal" de Herbert Blumer, que descrevemos no início deste texto. A teoria de Blumer, ainda que se situe num plano mais grupal, também refere que sentimentos de superioridade alimentam o preconceito. 


\subsection{SÍNTESE DAS EXPLICAÇ̃̃ES DO PRECONCEITO}

Ao longo deste capítulo, temos visto que o preconceito é um fenômeno complexo, de múltiplas facetas e causas, que simultaneamente reflete:

- Características dos indivíduos, desde as mais psicológicas e emocionais, até as mais sociais;

- Tipos de grupos envolvidos;

- Contextos e interesses nas relações entre eles;

- Tempos históricos e culturas que enquadram as relações.

Tendo isso em mente, Gordon Allport propôs a imagem de um telescópio como forma de explicar as causas do preconceito. De acordo com esse modelo, o preconceito pode ser entendido desde os seus determinantes históricos, decorrentes da relação entre os grupos; até os seus determinantes individuais ou de percepção de características nos indivíduos que impliquem na sua desvalorização; passando pela socialização, aprendizado e difusão das atitudes preconceituosas; para, finalmente, desembocar na "escolha" do tipo de vítima do preconceito, o que produzirá diferenças nas causas e formas de expressão do fenômeno (ver Figura 6).

Figura 6: Modelo do telescópio sobre os níveis de explicação do preconceito

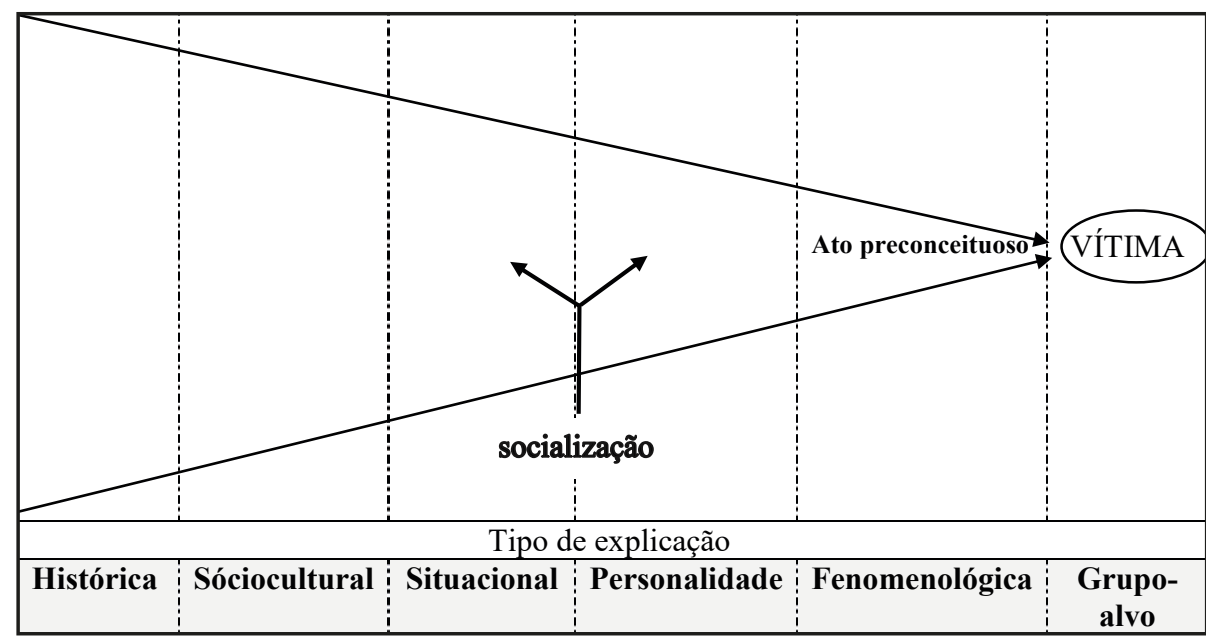

(Extraído de ALLPORT, 1979, p. 207) 
Analisando o Modelo de Allport, vemos que a perspectiva histórica é fundamental para entender as causas e formas de expressão do preconceito. Por exemplo, quando abordamos o preconceito racial no Brasil, é impossível entender o fenômeno sem considerar os impactos da escravidão e do mito da democracia racial. Da mesma forma, o surgimento de figuras como a de Hitler no século XX e o avanço do populismo autoritário na segunda década do século XXI são outros eventos históricos que criam um pano de fundo para o preconceito, afetando a escolha das vítimas e suas formas de expressão.

As explicações para o preconceito devem também levar em conta os aspectos socioculturais que envolvem as relações sociais. Quais são os valores centrais da nossa cultura? Qual a relação deles com o menosprezo pela diferença? Estudos mostram que há padrões diferentes de atitudes em sociedades mais individualistas em relação a outras mais coletivistas (TRIANDIS, 1989). É a imposição de modelos culturais, que definem espaços para os grupos, que determina o conteúdo dos estereótipos e dos preconceitos que eles instilam. Um dos traços mais centrais no estereótipo dos ciganos é o de que eles não são honestos; em relação às mulheres, é de que elas são frágeis; em relação aos negros, é de que são fisicamente fortes e, em relação aos homossexuais, é o de que são promíscuos. Os ciganos são vistos como desonestos porque ameaçam o modelo cultural hegemônico da ética do trabalho. As mulheres são vistas como frágeis porque devem se manter no espaço doméstico cuidando para que o homem ocupe os espaços da "rua". Os negros são vistos como fisicamente fortes porque devem executar os trabalhos braçais e mais mal pagos. $\mathrm{E}$, finalmente, os homossexuais vistos como promíscuos porque isso ajuda a "defender" modelos culturais tradicionalistas de família.

As dinâmicas específicas das relações intergrupais também devem ser levadas em conta nas explicações do preconceito, elas se relacionam mais diretamente com as explicações históricas e culturais apontadas por Allport. Nesse âmbito, a natureza do preconceito reflete as condições de interação social, ele é concebido como processo grupal e explicado por teorias que focam o conflito, a competição, as dinâmicas sociais e as relações de poder.

A ênfase nos fatores situacionais para explicar o preconceito, segundo Allport (1954), resulta na atualização contextual dos fatores históricos com os culturais. Trata-se da atmosfera particular onde somos socializados, em que aprendemos os valores da nossa cultura. Imagine que sua família é de classe média alta, vive num condomínio de alto padrão e você só frequenta ambientes com pessoas de mesmo estrato econômico. Vivendo no Brasil, nesse contexto, quantos amigos 
negros você acha que teria? O tipo de encontro e relação que estabelecemos com as outras pessoas têm impactos na nossa formação. Além disso, como vimos nesse texto, situações mais imediatas de conflito e competição ou, por outro lado, de cooperação e amizade, podem interferir nos preconceitos. Todavia, a relação nunca é simples e linear: ter mais amigos ou não ter amigos nem sempre significa ter menos ou mais preconceito. Na Tabela 1, podemos ver que essas explicações se enquadram naquelas que enfatizam como causa do preconceito a transmissão social de valores, sendo ele o resultado da socialização e aprendizado no âmbito de relações interpessoais; com destaque para as teorias sobre contato, socialização e normas sociais.

Mas, será que bastam os aportes histórico, cultural e situacional para explicar o preconceito? Nós vivemos praticamente nos mesmos contextos de socialização que nossos irmãos e amigos mais próximos. Mas será que a direção e a intensidade das nossas atitudes em relação às minorias sociais são idênticas? Se a resposta for não, então é porque fatores individuais também merecem destaque.

Allport (1954) aborda a influência da personalidade no preconceito considerando desde impulsos biológicos de dominínio ou poder sobre os outros, semelhantes aos que vimos na Teoria da Dominância Social; passando pelas explicações em termos da exposição dos indivíduos a frustrações, as quais podem levar a agir de forma preconceituosa (Frustração-Agressão); até focar tipos de personalidades, mais inseguras e ansiosas, que são mais sucetíveis a aprenderem e expressarem preconceitos, como vimos na Teoria da Personalidade Autoritária. Na Tabela 1, podemos ver que essas explicações supõem causas psicológicas ou biológicas, sendo o preconceito concebido como imanente nesse. Teorias de destaque nesse plano explicativo são: a Categorização Social, a Identidade Social, e aquelas que enfatizam mecanismos de projeção e deslocamento, tais como a da Frustração-Agressão e Personalidade Autoritária. Essas explicações se enquadram no âmbito das causas focadas em diferenças individuais, tendo o preconceito sua natureza modulada de forma diferente em cada indivíduo. Destacam-se as teorias sobre fatores cognitivos de ajustamento, adesão a ideologias políticas, nível da autoestima, dentre outras. Na parte final desse texto, você encontrará sugestões de materiais nos quais poderá obter mais informações sobre essas e outras explicações.

Cada contexto histórico, cultural, situacional e cada individualidade colaboram para um tipo de percepção e de consciência sobre os outros. O outro é, para nós, uma construção dinâmica, um tipo de representação mental e social; de 
modo que nossa interação com ele acontece nessa realidade construída, fenomênica (PEREIRA, 2019). Esse é outro nível de explicação possível para as causas do preconceito, o fenomenológico, que se refere ao modo como as percepções são produzidas e como impactam as relações sociais.

O modelo do telescópio de Allport também enfatiza o "efeito da vítima" nas explicações do preconceito. Há muitas formas de preconceito, elas possuem elementos comuns, mas variam em função do grupo-alvo. As causas do preconceito racial não são as mesmas da homofobia, do idadismo, do sexismo, da gordofobia. Mesmo dentro do preconceito racial ou étnico há variações a depender das minorias envolvidas. Allport (1954) chama a atenção para os "rótulos de potência primária". São aqueles que, pela sua força, nos levam a formar impressões sobre os outros com base em um único e central atributo, o qual configura e dá o tônus emocional e avaliativo de toda uma categoria social na imagem formada.

Imagine que você vai interagir com Sara, ela é mulher, negra, estudante de física e otaku, dentre muitos outros pertencimentos. O que vai pesar mais na imagem que você contrói sobre ela ou no estereótipo que é ativado na sua mente quando você a encontra? Provavelmente, algo muito complexo que depende do seu nível de racismo, de sexismo, interesse por Física, ou do quanto gosta de animes e mangás. Algo que também depende do contexto do encontro, se num simpósio de Física, ou noutro de cultura japonesa, ou, ainda, numa tensa discussão política sobre cotas sexuais e raciais. De toda forma, aquilo que nas interações mais imediatas e superficiais vemos primeiro numa pessoa, como o seu gênero e a cor da sua pele, na maior parte dos casos, funcionam como os tais "rótulos de potência primária", que poderão atuar como verdadeiros reagentes químicos na percepção dos outros atributos de uma pessoa.

O tipo de minoria social impacta, além do processo de ativação dos estereótipos e da acessibilidade do preconceito, o conteúdo destes. O antijudaismo, por exemplo, se ampara mais em elementos de ameaça real entre os grupos que a islamofobia, a qual se baseia mais na ameaça simbólica ou cultural. $\mathrm{O}$ preconceito contra indígenas urbanos é diferente do que é expresso contra indígenas rurais. Questões identitárias podem estar na base da homofobia, mas elas certamente não são tão importantes para explicar o preconceito contra idosos. A ideologia do paternalismo estrutura muito do sexismo, do preconceito contra idosos e até do racismo contra os negros, mas é inócua na homofobia e no racismo contra os ciganos.

Na Tabela 1, tentamos esquematizar o que foi abordado neste texto. Destacamos as causas psicológicas, intergrupais, da socialização ou transmissão social 
e individual; a natureza do preconceito, imanente, apreendido, modulado nas interações; os níveis adotados na sua análise, os quais se relacionam com as suas causas, psicológico, grupal, interpessoal e individual; e, finalmente, as principais teorias construídas para o seu entendimento, as quais também se conectam com as causas assumidas, com as crenças sobre a sua natureza e com os níveis de análise adotados. Todas essas dimensões, portanto, se encadeiam para tentar entender este antigo e ainda relevante problema das relações humanas. Importante referir aqui que não esgotamos, muito longe disso, as teorias sobre o preconceito e suas causas. Tentamos realizar apenas uma breve introdução sobre elas e apontar alguns caminhos de leitura e reflexão mais aprofundados. Na segunda parte deste capítulo sobre preconceito, vamos analisar como o processamento da informação interfere sua gênese e na pesquisa psicossocial sobre ele.

Tabela 1: Estrutura integrativa das explicações para o preconceito

\begin{tabular}{|c|c|c|c|c|}
\hline Causas & Psicológicas & $\begin{array}{l}\text { Dinâmicas das } \\
\text { relações intergrupais }\end{array}$ & $\begin{array}{c}\text { Transmissão } \\
\text { social }\end{array}$ & $\begin{array}{l}\text { Diferenças } \\
\text { individuais }\end{array}$ \\
\hline $\begin{array}{c}\text { Natureza do } \\
\text { processo }\end{array}$ & $\begin{array}{l}\text { Imanente e } \\
\text { universal }\end{array}$ & $\begin{array}{l}\text { Condições da } \\
\text { interação social }\end{array}$ & $\begin{array}{c}\text { Socialização e } \\
\text { aprendizado das } \\
\text { atitudes } \\
\text { preconceituosas }\end{array}$ & $\begin{array}{c}\text { Modulação } \\
\text { individual das } \\
\text { influências sociais } \\
\text { (diferenças } \\
\text { individuais) }\end{array}$ \\
\hline $\begin{array}{l}\text { Níveis de } \\
\text { análise }\end{array}$ & Psicológico & Grupal & Interpessoal & Individual \\
\hline Teorias & $\begin{array}{l}\text { - Deslocamento } \\
\text { - Semelhança de } \\
\text { crenças } \\
\text { - Projeção } \\
\text { - Categorização } \\
\text { social } \\
\text { - Identidade social } \\
\text { - Sociobiológicas }\end{array}$ & $\begin{array}{c}\text { - Conflito real } \\
\text { - Competição social } \\
\text { - Dominância social } \\
\text { - Posição grupal e } \\
\text { poder }\end{array}$ & $\begin{array}{l}\text { - Pressão para a } \\
\text { conformidade } \\
\text {-Socialização } \\
\text {-Percepção e } \\
\text { Atribuição social } \\
\text { - Contato } \\
\text { interpessoal }\end{array}$ & $\begin{array}{c}\text { - Autoritarismo } \\
\text { - Frustração } \\
\text { - Ajustamento } \\
\text { - Fatores cognitivos } \\
\text { - Ideologia política } \\
\text { - Autoestima }\end{array}$ \\
\hline
\end{tabular}

(Adaptada de DUCKITT, 1992, p. 1190) 